\title{
A crossover study of short burst oxygen therapy (SBOT) for the relief of exercise-induced breathlessness in severe COPD
}

\author{
B Ronan O'Driscoll*, Jane Neill, Siddiq Pulakal and Peter M Turkington
}

\begin{abstract}
Background: Previous small studies suggested SBOT may be ineffective in relieving breathlessness after exercise in COPD

Methods: 34 COPD patients with FEV1 $<40 \%$ predicted and resting oxygen saturation $\geq 93 \%$ undertook an exercise step test 4 times. After exercise, patients were given $4 \mathrm{l} / \mathrm{min}$ of oxygen from a simple face mask, $4 \mathrm{l} / \mathrm{min}$ air from a face mask (single blind), air from a fan or no intervention.
\end{abstract}

Results: Average oxygen saturation fell from $95.0 \%$ to $91.3 \%$ after exercise. The mean time to subjective recovery was 3.3 minutes with no difference between treatments. The mean Borg breathlessness score was 1.5/10 at rest, rising to 5.1/10 at the end of exercise (No breathlessness $=0$, worst possible breathlessness $=10$ ). Oxygen therapy had no discernable effect on Borg scores even for 14 patients who desaturated below 90\%. 15 patients had no preferred treatment, 7 preferred oxygen, 6 preferred the fan, 3 preferred air via a mask and 3 preferred room air.

Conclusions: This study provides no support for the idea that COPD patients who are not hypoxaemic at rest derive noticeable benefit from oxygen therapy after exercise. Use of air from a mask or from a fan had no apparent physiological or placebo effect.

\section{Background}

Oxygen therapy is beneficial for many patients with chronic obstructive pulmonary disease (COPD). It is used to correct dangerous hypoxaemia in acute exacerbations of COPD and it is known that long term oxygen therapy (LTOT) can prolong life expectancy in patients with COPD who have got chronic hypoxaemia, especially if there is evidence of cor pulmonale [1-3]. It has also been demonstrated that the use of ambulatory oxygen therapy during exercise tests in the laboratory can increase exercise distance and reduce exercise-induced breathlessness in patients with COPD who desaturated during exertion although the reported benefits in the home environment were less impressive [4-7]. The most controversial form of oxygen therapy in COPD is known as short burst oxygen therapy (SBOT) [8]. This involves the use of oxygen either before or, more

\footnotetext{
* Correspondence: ronan.o.driscoll@srft.nhs.uk

Manchester Academic Health Science Centre University of Manchester Salford Royal University Hospital Stott Lane, Salford M6 8HD UK
}

commonly, after exercise by patients with COPD who are not hypoxaemic at rest. This form of treatment appears to be especially common in the UK where it is estimated that about $£ 18$ million (approximately $\$ 25$ million) per annum is spent on oxygen cylinders that are used in patients' homes [9] although there is very little evidence to support this practice. Previous shortterm studies of SBOT for patients with COPD involved small numbers of patients and most of the trials failed to demonstrate any benefit from the use of SBOT either before or after exercise [10-19]. In one long-term study [20], patients who were randomized to "SBOT" using either oxygen or a placebo cylinder (air) over a six month period had high initial use of both types of cylinder and very low use subsequently and there was no difference between the use of oxygen or air cylinders. Two systematic reviews have concluded that the published studies do not support the use of SBOT for patients with COPD $[8,21]$. It has been suggested that some of the apparent benefits from oxygen therapy may be due

\section{Biomed Central}


to reflex mechanisms in response to a flow of cool air on the face or nose $[22,23]$.

We conducted a partially single-blind study of oxygen compared with air from a face mask in patients with severe COPD who were not hypoxaemic at rest. Our aim was to determine if patients given oxygen would recover more quickly from exercise-induced breathlessness compared with patients given air. We also evaluated the possibility that patients might derive symptomatic benefit from having a flow of air delivered to the face by an electric fan.

\section{Methods}

This trial was designed as a partially single-blind crossover assessment of the short-term response to SBOT amongst a group of patients attending the outpatient service in a University Hospital with severe COPD and limitation of activities of daily living due to breathlessness. The co-primary objectives were to determine whether SBOT given after exercise to non-hypoxaemic patients with COPD can (a) reduce dyspnoea during recovery from exercise or (b) shorten the recovery period. Oxygen therapy was compared with room air, compressed air from a face-mask or air blown on the face by an electric fan.

The secondary objectives were to determine; 1 . Whether there is any difference in dyspnoea and time to recovery if a patient breathes room air, room air blown by an electric fan or compressed air via face mask; 2 . Whether there is any difference in the subjective response to oxygen between patients who desaturate on exercise ( $\mathrm{SpO} 2$ below $90 \%$ on at least two occasions during or after exertion in this study) and those who do not 3. Whether the subjective benefit from oxygen noted in some previous studies was due to a cooling airflow on the face or a physiological benefit from Oxygen.

Patients were recruited from the chest clinic or pulmonary rehabilitation service at Salford Royal University Hospital. We recruited only patients who experienced significant breathlessness on minor exertion and who wished to be considered for symptomatic treatment with oxygen (SBOT) at home. Eligible patients were invited to take part in the study and given an information leaflet describing the study, with opportunities to ask questions of a doctor or respiratory nurse specialist prior to inclusion in the trial. Written informed consent was obtained before each patient could enter the study and the trial protocol was approved by the Salford and Trafford Local Research Ethics Committee, reference 04/ Q1404/21.

\section{Inclusion Criteria}

Patients aged over 50 years with smoking history of more than 20 pack years; Severe COPD with FEV1 less than $40 \%$ predicted value;[24] Oxygen saturation at rest $\geq 93 \%$ breathing room air at time of recruitment to study and on arrival on study day; Breathless during modest exercise such as climbing one or two flights of stairs; Stable for 4 weeks (Not requiring oral steroids or antibiotics or both); Able to give informed consent; Able to undertake a simple step test on an $18 \mathrm{~cm}$ exercise step.

\section{Exclusion Criteria}

Unable or unwilling to give informed consent; Unable or unwilling to undertake step test for any reason; Complicating co-morbid conditions (e.g. arthritis of knees) which might interfere with exercise test or with the conduct of trial; Patients already using oxygen cylinders at home.

All exercise tasks were supervised by a single observer (JN). On the study day, patients completed the following procedures; The Oxygen saturation $\left(\mathrm{SpO}_{2}\right)$ and baseline pulse were measured using a single Minolta Pulsox-3 oximeter. A Borg Dyspnoea score [25] (0 = not breathless, $10=$ maximal breathlessness) was administered after at least 10 minutes of rest in a seated position. The patient then performed the first of four exercise step tests by stepping on and off a standard $18 \mathrm{~cm}$ exercise step as previously described [26,27]. Patients were instructed to exercise for up to 3 minutes at the fastest sustainable pace that was comfortable for them. The patients were instructed to stop before 3 minutes if they felt that they had reached comfortable limits (for whatever reason). The oxygen saturation and pulse rate were monitored continuously using the same finger oximeter for every test. The $\mathrm{SpO} 2$ and pulse rate were recorded in the patient's trial record sheet each minute during the exercise test, at the end of exercise and every minute during recovery until 5 minutes after finishing the exercise task. Patients completed a modified Borg dyspnoea score before and immediately after the exercise task and every minute for 5 minutes during the recovery period. The investigator recorded the objective recovery time defined as the time when the pulse rate had recovered to within five beats per minute of the baseline pulse. The subjective recovery time was measured by asking patients every minute during the recovery period if their sense of breathlessness had returned to the level that it was at before exercise.

Patients rested for at least 30 minutes after full recovery from each exercise task and they undertook a total of four exercise tasks on the same day. Immediately after completing each exercise task, patients received one of the following interventions in random order based on the patient drawing four pieces of folded paper sequentially from an opaque container prior to the commencement of the exercise task. Each piece of paper 
contained a single letter which determined the order of treatment as follows: a) Room air (no intervention). b) Use of an electric fan with $28 \mathrm{~cm}$ blades to blow cool air on the face from a distance of one meter (Type FT30 fan from Guangdong Zhongshan Household Electric Appliance General Factory, China; set at highest speed setting). c) Air at 4 liters per minute from a simple face mask (Venticaire medium concentration oxygen mask, from Flexicare Medical Limited UK). d) Oxygen at 4 liters per minute (approximately 35\% oxygen) from the same mask in a single blind manner. Allocation to treatment order took place after all other aspects of trial recruitment to avoid any possible recruitment bias. The oxygen and air treatments were single blind. To achieve blinding for these two interventions, the investigator connected a concealed air or oxygen cylinder delivering a gas flow of 4 liters per minute to the same face mask for each patient.

\section{Statistics}

The study of Nandi et al [18] was used to determine the number of subjects required for the trial. We estimated that a crossover study involving 40 patients would have $80 \%$ power to detect a significant difference in the objective recovery time comparing oxygen with air. All data were entered in a scientific database (Graph Pad Prism4) and analyzed in that database. Data for each group were compared using Wilcoxon matched pairs test.

\section{Results}

39 patients were recruited and gave written informed consent to take part in the study. Three patients were found to have recent FEV1 above $40 \%$ predicted and their results were not analyzed. One patient was hypoxaemic breathing air when he attended for the study $\left(\mathrm{SpO}_{2} 88 \%\right)$ and one patient withdrew from the study after one of the four exercise tasks. Details of the 34 patients who completed the study are shown in Table 1.

\section{Table 1 Details of 34 patients who completed the trial}

\begin{tabular}{llll}
\hline & Mean & Standard Deviation & Range \\
\hline Age (years) & 67.5 & 8.9 & $52-87$ \\
FEV1 (liters) & 0.80 & 0.2 & $0.45-1.3$ \\
FEV1 as \%predicted & $31.4 \%$ & 5.5 & $21-39$ \\
Number of steps climbed & 35.0 & 18.2 & $7-115$ \\
Exercise time (seconds) & 93.9 & 43.1 & $23-180$ \\
SpO2at rest & 95.0 & 1.3 & $92-98$ \\
SpO2 at end of exercise & 91.3 & 3.8 & $79-97$ \\
Pulse at rest & 86.1 & 12.4 & $51-117$ \\
Pulse at end of exercise & 103 & 17.8 & $57-145$ \\
Borg score at rest & 1.5 & 1.1 & $0-4$ \\
Borg score at end of exercise & 5.1 & 1.6 & $2-9$ \\
\hline
\end{tabular}

(24 male, 10 female; 4 current smokers, 30 ex-smokers).
Patients climbed an average of 35 steps in an average of 94 seconds. The mean number of steps climbed (SD) was as follows. First task 34.9 steps (22.6); second task 35.1 steps (17.2); third task 35.2 steps (16.8); fourth task 35.0 steps (16.3). The patients' oxygen saturation and pulse rates were well matched before each exercise task and at the end of each of the four exercise periods as shown in table 2.

The mean oxygen saturation fell from $95.0 \%$ pre-exercise to $91.3 \%$ at the end of the exercise task and the speed of $\mathrm{SpO} 2$ recovery to the baseline level was almost identical when room air, mask air and the electric fan were used in the recovery period (Figure 1). Oxygen saturation rose more quickly and to a higher level when the oxygen mask was used $(\mathrm{p}<0.009$ compared with the other treatments at 1 minute and $<0.0001$ thereafter). However, this increase in oxygen saturation of about $2 \%$ had no effect on the subjective sense of breathlessness as measured by the Borg score during the recovery period (Figure 2). The breathlessness score was about half a Borg unit higher when the air-mask was used compared with the other three groups at 1 and 2 minutes after finishing the exercise task $(\mathrm{p}=0.01)$, possibly reflecting increased resistance due to the mask. Table 2 shows that the subjective recovery times were very similar for each of the four interventions with no significant difference between any of them. However, the pulse recovery time was almost a minute shorter when oxygen was given (Figure 3 ). This achieved statistical significance compared with room air $(\mathrm{p}<0.01)$ and compared with air from a mask $(p=0.03)$ but not compared with air from a fan $(\mathrm{p}=0.16)$.

The same pattern of oxygenation, Borg scores and recovery times was seen amongst the 14 patients who desaturated below $90 \%$ as was seen for the entire cohort with no significant difference in the Borg score at any time point or in the subjective recovery time compared with air. (Table 2 and right hand panels of Figures 1 and 2).

After completing the four exercise tasks, each patient was asked about their preferred treatment. Fifteen patients had no overall preference. Of the 19 patients who expressed a preference, 7 chose the oxygen mask, 6 chose the electric fan, 3 chose air from a mask and 3 preferred room air. The seven patients who expressed a preference for oxygen amounted to only $21 \%$ of the overall group. Five of these seven patients $(71 \%)$ had desaturated during exercise compared with nine of 27 (33\%) patients who did not have a preference for oxygen therapy but this difference did not reach statistical significance (Fisher's exact test $\mathrm{p}=0.097$ ).

\section{Discussion}

Despite a rapid rise in oxygen saturation, COPD patients in this study reported no reduction in post-exertion 
Table 2 Summary of responses to exercise and treatments

\begin{tabular}{lcccc}
\hline & Room Air & Electric Fan & Air Mask & Oxygen Mask \\
\hline Mean exercise time (seconds) & $93.7(42.1)$ & $92.9(43.2)$ & $94.1(40.5)$ & $93.0(46.1)$ \\
Mean number of steps climbed & $34.1(17.0)$ & $36.0(17.1)$ & $36.6(21.9)$ & $33.4(16.8)$ \\
Mean pulse pre-exercise & $86.0(12.1)$ & $87.3(13.1)$ & $84.7(12.0)$ & $86.2(12.6)$ \\
Mean pulse at end of exercise & $99.3(18.6)$ & $103.6(16.6)$ & $107.0(19.7)$ & $102.1(16.2)$ \\
Mean SpO 2 pre-exercise & $95.2(1.4)$ & $94.8(1.3)$ & $95.1(1.3)$ & $94.9(1.3)$ \\
Mean SpO at end of exercise & $91.3(4.0)$ & $91.1(3.7)$ & $91.3(4.3)$ & $91.5(3.5)$ \\
Mean Borg score pre-exercise & $1.5(1.1)$ & $1.5(1.2)$ & $1.5(1.1)$ & $1.6(1.2)$ \\
Mean Borg score at end of exercise & $5.1(1.7)$ & $5.1(1.7)$ & $3.3(1.6)$ & $3.1(1.7)$ \\
Mean subjective recovery time (mins) & $3.2(1.1)$ & $3.6(1.8)$ & $2.9(2.5)$ & $3.1(1.2)$ \\
Mean objective recovery time (mins) & $2.8(2.0)$ & & & $1.9(1.0)$ \\
Recovery time for sub-group of 14 patients who desaturated & $3.2(1.1)$ & $3.4(1.1)$ & $3.5(0.9)$ & $3.6(3.6)$ \\
Mean subjective recovery time (mins) & $3.0(1.8)$ & $2.1(0.9)$ & & $1.9(1.0)$ \\
Mean objective recovery time (mins) & & & \\
\hline
\end{tabular}

(Mean and SD).

breathlessness and no shortening of subjective recovery time when oxygen was given by simple face mask at $4 \mathrm{l} /$ min compared with air from the same face mask or compared with a fan blowing air on the face or no intervention. This was true for the full group of 34 patients and for the sub-group of 14 patients who desaturated below $90 \%$ during exercise. The Borg score was about half a unit higher (worse breathlessness) when the air mask was used. Although this slight increase in breathlessness may have been caused by increased resistance to breathing due to the tight-fitting mask, the difference was probably too small to be clinically relevant. The pulse recovery time was shorter when oxygen was given but this did not seem to provide any symptomatic benefit. Quantrill [12] reported a small improvement of about 35 seconds in the subjective and objective recovery times when oxygen was given after exercise to patients with COPD who were already using SBOT at home and who reported benefit from it's use. However, these differences did not reach statistical significance and only 5 of 22 patients could correctly identify oxygen from air in Quantrill's single-blind study.

The present study was larger than all previously published studies of the effect of short burst oxygen therapy for the relief of breathlessness after exertion for COPD patients. The overall negative results are in line with the majority of previous studies [10-19] and with two systematic reviews of short burst oxygen therapy $[8,21]$.

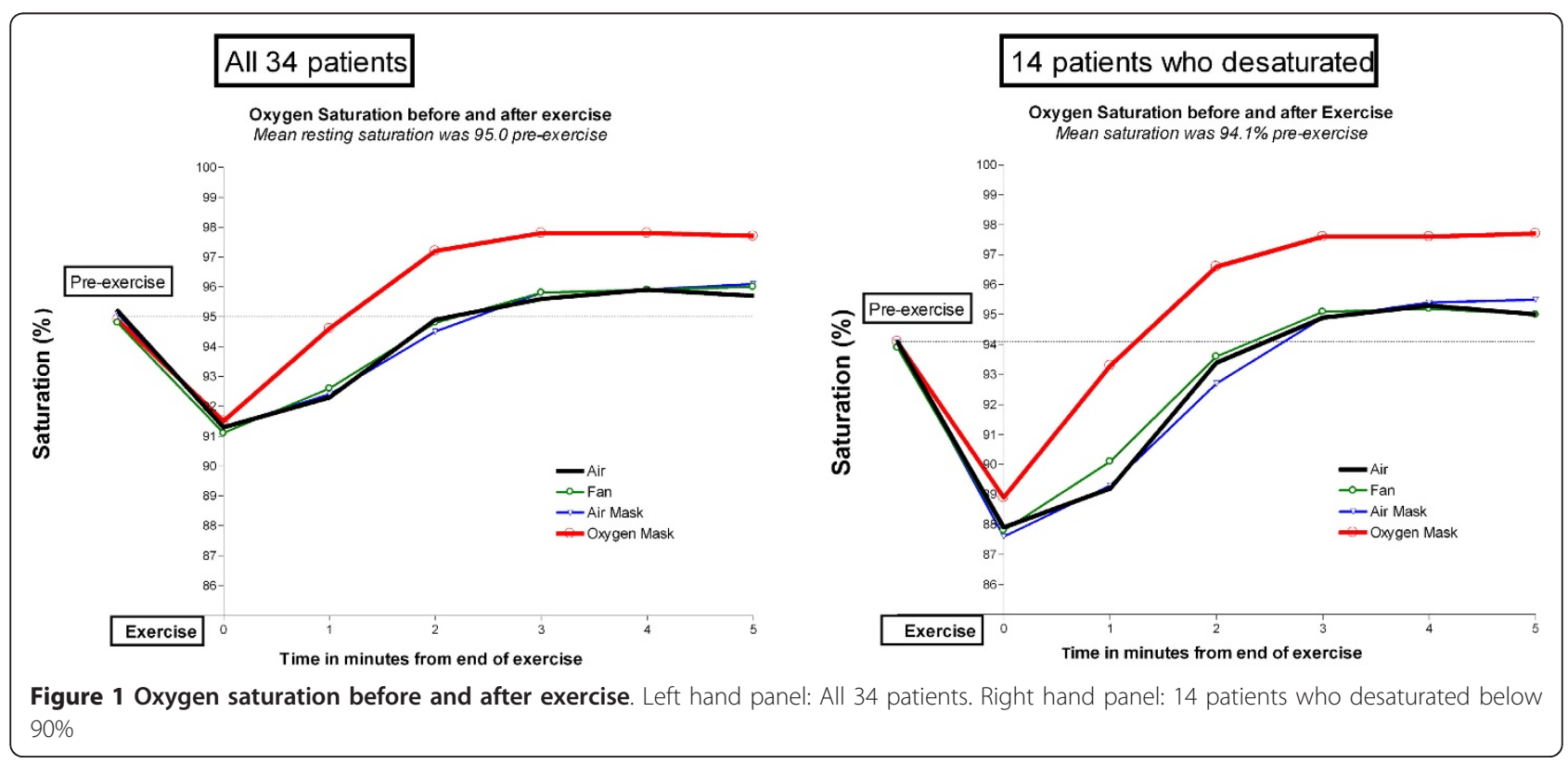




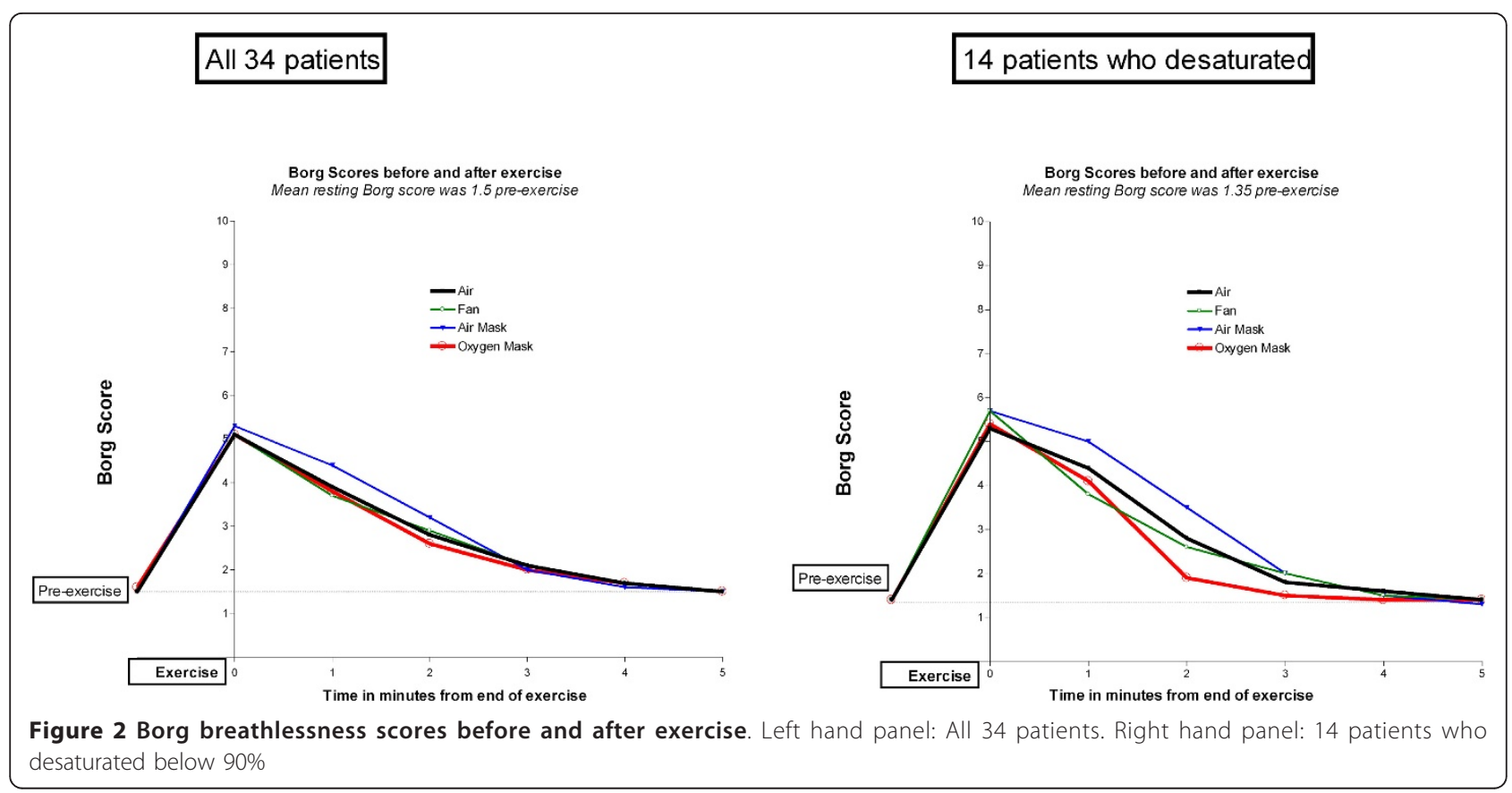

Some authors have suggested that cooling of the face or nose may reduce breathlessness by reflex actions $[22,23]$. However, we found that none of three interventions which involved gas flow over the face in the present study (air mask, oxygen mask or electric fan) had any significant effect on the patients' sensation of breathlessness after exertion. This suggests that any substantial physiological effect (or placebo effect) from airflow from masks or fans on the face is unlikely.

The Borg breathlessness scores were higher at one and two minutes post exercise when air was given by face mask at 41 /minute (Figure 2). This effect was small but statistically significant $(\mathrm{p}<0.01$ compared with fan at one minute and compared with oxygen at two minutes and $\mathrm{p}<0.04$ compared with room air at one minute) and it was more marked for the 14 patients who desaturated (Figure 2, right hand panel). This might be due to the high respiratory rate in this group leading to a slight resistance to inspiration caused by inhaling from a small volume mask entraining a low flow of air [28].

Although the present study is not large, it is the largest laboratory study of SBOT yet conducted and the crossover design on a single day yielded very stable baseline values which made the comparison between

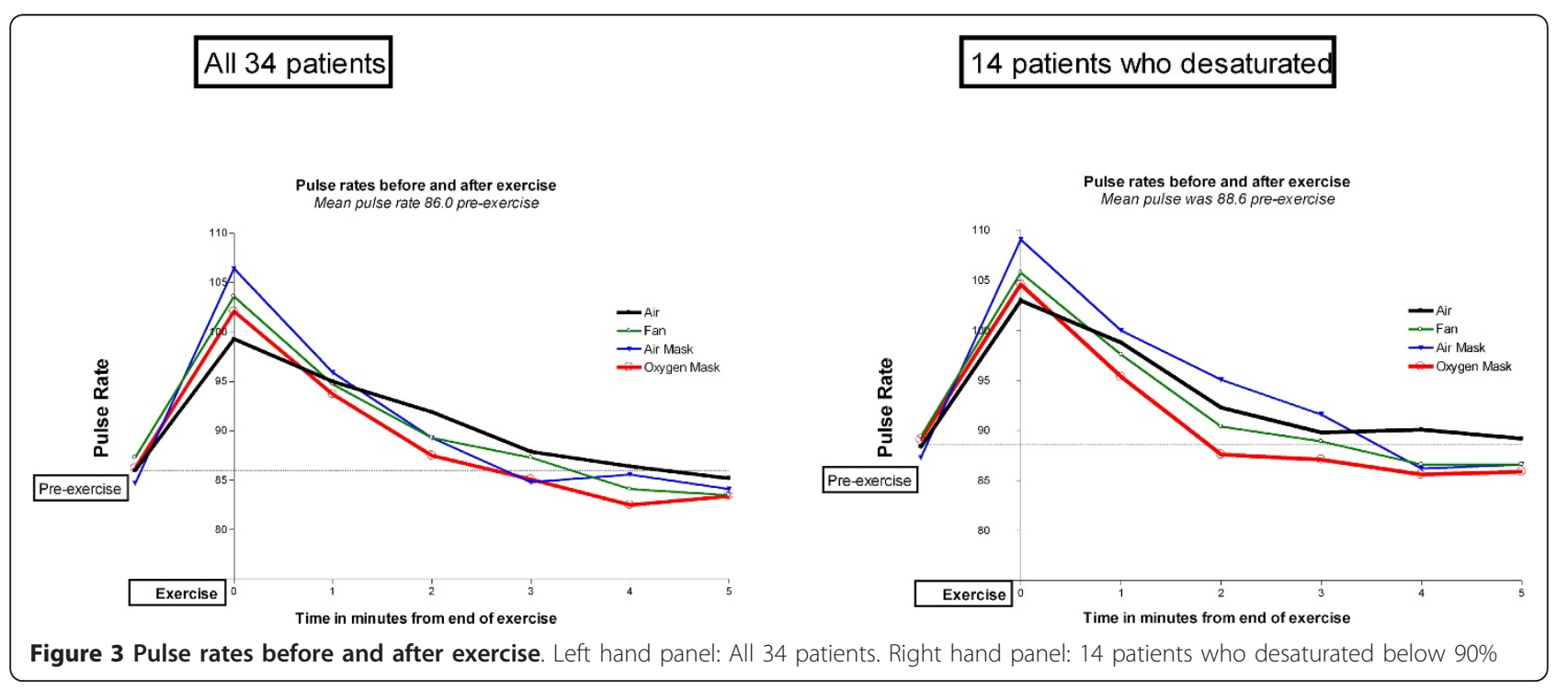


treatments more robust. We did not achieve our recruitment target of 40 patients but the standard deviation of the Borg score post exercise (1.6) was lower than that the value of 1.8 which was reported in a previous similar study [19]. The achieved sample size of 34 patients gave a power of 0.94 to detect a difference of 1 Borg unit with a probability of type 1 error of 0.05 .

The exercise step test is not as well validated in COPD as the 6 minute walk test or the shuttle walk test $[29,30]$. However, this test has been validated in previous studies $[26,27]$ and there was excellent reproducibility with no learning effect from the first to the fourth exercise task in the present study which would further validate this test. A further advantage of the step test is that it is similar to the sort of activity such as stair climbing for which patients actually use SBOT in clinical practice [12]. Furthermore, the step test can be carried out in one to three minutes within the consulting room as part of a routine consultation but few clinics have sufficient staff time or floor-space to permit the use of 6 minute walks or shuttle walk tests within a routine consultation.

We observed no order effect in the present study . It is not known if any other outcome measure would be superior to the Borg score but the lack of benefit in Borg scores was reflected in the finding that only seven of 34 patients preferred oxygen compared with the other interventions. Five of these seven patients had desaturated during exercise. Although this was not statistically significant it raises the possibility that a larger study of "desaturators" might identify a small group of patients who could gain benefit from short burst oxygen therapy.

The present trial is in agreement with the majority of previous studies [10-19] in finding no overall improvement in the mean Borg breathlessness score when oxygen was given after exercise, even for the 14 patients who had experienced desaturation during the exercise task and despite a rapid rise in $\mathrm{SpO} 2$ on oxygen therapy and a quickening of the pulse recovery time. As none of the previous studies have reported large improvements in breathlessness in response to SBOT, the addition of the present study to the previous studies strengthens the current consensus view $[1,8,21]$ that there is no clinically important benefit for most users of SBOT. By contrast, there is strong evidence of benefit from pulmonary rehabilitation for patients with COPD [31] and we would recommend this as the preferred option for patients who remain breathless on exertion despite maximal medical treatment for COPD.

Although it remains possible that a minority of patients might benefit from short burst oxygen therapy, ambulatory oxygen therapy (to prevent desaturation during exercise) might be more effective for such patients but it is not widely used at present for patients who are not hypoxaemic at rest. The GOLD (Global initiative for chronic Obstructive Lung Disease) Guideline [32] does not make any recommendation for or against the use of SBOT for patients with COPD. The British National Institute for Health and Clinical Excellence (NICE) has recommended that short burst oxygen treatment should "only be considered for episodes of severe breathlessness in patients with COPD not relieved by other treatments.... and only if an improvement in breathlessness following therapy has been documented." [1] Our study provides further support for this advice.

\section{Conclusions}

This study provides no support for the idea that COPD patients who are not hypoxaemic at rest derive noticeable benefit from oxygen therapy after exercise. This negative result was in agreement with most previous short-term trials of SOBT in patients with COPD. Use of air from a mask or from a fan had no apparent physiological or placebo effect. We would suggest that SBOT should not be prescribed without a formal exercise assessment such as that described in the present study and it should be prescribed for home use only if a patient with severe COPD has desaturated on exertion with demonstrable improvement in breathlessness on oxygen compared with air in a single-blind study and the prescription should be continued only if there is consistent use of the SBOT treatment over a period of several months.

\section{Author' information}

SP now works as a consultant respiratory physician at the University Hospital of South Manchester, Manchester M23 9RT

\section{Abbreviations}

COPD: Chronic Obstructive Pulmonary Disease; LTOT: Long Term Oxygen Therapy; SBOT: Short Burst Oxygen Therapy.

\section{Acknowledgements}

All authors contributed to the design of the study and patient recruitment. $\mathrm{JN}$ and SP undertook the trial procedures and recorded the results. ROD analysed the data and prepared the draft manuscript and all authors edited and approved the final manuscript.

The authors would like to thank Dr Andrew Vale for expert statistical Advice. This study was funded by the Salford Respiratory Fund which is a registered charity.

\section{Authors' contributions}

All authors were involved in the design of the study. JN and SP recruited patients and also undertook the trial interventions and data entry into a computer database. RO'D analysed the data and wrote the text of the paper and all authors were involved in proofreading and editing the paper prior to submission for publication. All authors read and approved the final manuscript.

\section{Competing interests}

The authors declare that they have no competing interests. 
Received: 17 November 2010 Accepted: 13 May 2011

Published: 13 May 2011

\section{References}

1. National Institute for Clinical Excellence. NICE Guideline CG101. Chronic Obstructive Pulmonary Disease (2010 update). http://www.nice.org.uk/ nicemedia/live/13029/49425/49425.pdf (2011)

2. Nocturnal Oxygen Therapy Trial Group, Continuous or nocturnal oxygen therapy in hypoxemic chronic obstructive lung disease: a clinical trial. Annals of Internal Medicine. 93(3):391-398 (1980)

3. Report of the Medical Research Council Working Party, Long-term domiciliary oxygen therapy in chronic hypoxic cor pulmonale complicating chronic bronchitis and emphysema. Lancet. 1, 681-685 (1981)

4. JM Bradley, T Lasserson, S Elborn, J Macmahon, B O'Neill, A systematic review of randomized controlled trials examining the short-term benefit of ambulatory oxygen in COPD. Chest. 131, 278-285 (2007). doi:10.1378/ chest.06-0180

5. T Eaton, JE Garrett, P Young, W Fergusson, J Kolbe, S Rudkin, K Whyte, Ambulatory oxygen improves quality of life of COPD patients: a randomized controlled study. Eur Respir J. 20, 306-312 (2002). doi:10.1183/ 09031936.02 .00301002

6. CF McDonald, CM Blyth, MD Lazarus, I Marschner, CE Barter, Exertional oxygen of limited benefit in patients with chronic obstructive pulmonary disease and mild hypoxemia. Am J Respir Crit Care Med. 152, 1616-1619 (1995)

7. Y Lacasse, R Lecours, C Pelletier, R Bégin, F Maltais, Randomised trial of ambulatory oxygen in oxygen-dependent COPD. Eur Respir J. 25, 1032-1038 (2005). doi:10.1183/09031936.05.00113504

8. BR O'Driscoll, Short burst oxygen therapy in patients with COPD. Monaldi Arch Chest Dis. 69, 70-74 (2008)

9. NHS Information Centre, Prescription cost analysis: England 2005. http:// www.ic.nhs.uk/webfiles/publications/prescostanalysis2005/ PrescriptionCostAnalysis110406_PDF.pdf (2005). Accessed May 2011

10. NJ Stephenson, PMA Calverly, Effect of oxygen on recovery from maximal exercise in patients with chronic obstructive pulmonary disease. Thorax. 59, 668-672 (2004). doi:10.1136/thx.2003.014209

11. AA Woodcock, ER Gross, DM Geddes, Oxygen relieves breathlessness in "pink puffers". Lancet. 1(8226):907-909 (1981)

12. SJ Quantrill, R White, A Crawford, JS Barry, S Batra, P Whyte, CM Roberts, Short burst oxygen therapy after activities of daily living in the home in chronic obstructive pulmonary disease. Thorax. 62, 702-705 (2007). doi:10.1136/thx.2006.063636

13. TW Evans, JC Waterhouse, A Carter, JF Nicholl, P Howard, Short burst oxygen treatment for breathlessness in chronic obstructive airways disease. Thorax. 41, 611-615 (1986). doi:10.1136/thx.41.8.611

14. JL McKeon, K Murree-Allen, NA Saunders, Effects of breathing supplemental oxygen before progressive exercise in patients with chronic obstructive lung disease. Thorax. 43, 53-56 (1988). doi:10.1136/thx.43.1.53

15. CR Swinburn, H Mould, TN Stone, PA Corris, GJ Gibson, Syptomatic benefit of supplemental oxygen in hypoxemic patients with chronic lung disease. Am Rev Respir Dis. 143, 913-915 (1991)

16. JA Marques-Magallanes, TW Storer, CB Cooper, Treadmill exercise duration and dyspnea recovery time in chronic obstructive pulmonary disease: effects of oxygen breathing and repeated testing. Respir Med. 92, 735-738 (1998). doi:10.1016/50954-6111(98)90004-X

17. JW Killen, PA Corris, A pragmatic assessment of the placement of oxygen when given for exercise induced dyspnoea. Thorax. 55, 544-546 (2000). doi:10.1136/thorax.55.7.544

18. K Nandi, AA Smith, A Crawford, KD MacRae, R Garrod, WA Seed, CM Roberts, Oxygen supplementation before or after submaximal exercise in patients with chronic obstructive pulmonary disease. Thorax. 58, 670-673 (2003). doi:10.1136/thorax.58.8.670

19. CA Lewis, TE Eaton, P Young, J Kolbe, Short-burst oxygen immediately before and after exercise is ineffective in nonhypoxic COPD patients. Eur Respir J. 22, 584-588 (2003). doi:10.1183/09031936.03.00027603a

20. T Eaton, W Fergusson, J Kolbe, CA Lewis, T West, Short-burst oxygen therapy for COPD patients: a 6-month randomised, controlled study. Eur Respir J. 27, 697-704 (2006). doi:10.1183/09031936.06.00098805

21. B O'Neill, JM Mahon, J Bradley, Short-burst oxygen therapy in chronic obstructive pulmonary disease. Respir Med. 100, 1129-1138 (2006). doi:10.1016/..rmed.2006.03.038
22. RM Schwartzstein, K Lahive, A Pope, SE Weinberger, JW Weiss, Cold facial stimulation reduces breathlessness induced in normal subjects. Am Rev Respir Dis. 136, 58-61 (1987)

23. DP Spence, DR Graham, J Ahmed, K Rees, MG Pearson, PM Calverley, Does cold air affect exercise capacity and dyspnea in stable chronic obstructive pulmonary disease? Chest. 103, 693-696 (1993). doi:10.1378/chest.103.3.693

24. BTS guidelines for the management of chronic obstructive pulmonary disease, The COPD Guidelines Group of the Standards of Care Committee of the BTS. Thorax. 52(Suppl 5):S1-28 (1997)

25. G Borg, Psychophysical bases of perceived exertion. Med Sci Sports Exerc. 14, 377-381 (1982)

26. KO Hadeli, EM Siegel, DL Sherrill, KC Beck, PL Enright, Predictors of oxygen desaturation during submaximal exercise in 8,000 patients. Chest. 120 88-92 (2001). doi:10.1378/chest.120.1.88

27. E Flynn, R O'Driscoll, Exercise testing in the consulting room. Chest. 122 383 (2002). doi:10.1378/chest.122.1.383

28. BR O'Driscoll, LS Howard, AG Davison, British Thoracic Society, BTS guideline for emergency oxygen use in adult patients. Thorax. , Suppl 6: vi1-68 (2008)

29. PL Enright, The six-minute walk test. Respir Care. 48, 783-785 (2003)

30. SM Revill, MD Morgan, SJ Singh, J Williams, AE Hardman, The endurance shuttle walk: a new field test for the assessment of endurance capacity in chronic obstructive pulmonary disease. Thorax. 54, 213-222 (1999). doi:10.1136/thx.54.3.213

31. Y Lacasse, R Goldstein, TJ Lasserson, S Martin, Pulmonary rehabilitation for chronic obstructive pulmonary disease. Cochrane Database of Systematic Reviews. , 4: CD003793 (2006)

32. Global Initiative for Chronic Obstructive Lung Disease, Global strategy for the diagnosis, management and prevention of chronic obstructive pulmonary disease: NHLBI/WHO workshop report, updated 2007. http:// www.goldcopd.org (2010)

\section{Pre-publication history}

The pre-publication history for this paper can be accessed here: http://www.biomedcentral.com/1471-2466/11/23/prepub

doi:10.1186/1471-2466-11-23

Cite this article as: O'Driscoll et al: A crossover study of short burst oxygen therapy (SBOT) for the relief of exercise-induced breathlessness in severe COPD. BMC Pulmonary Medicine 2011 11:23.

\section{Submit your next manuscript to BioMed Central and take full advantage of:}

- Convenient online submission

- Thorough peer review

- No space constraints or color figure charges

- Immediate publication on acceptance

- Inclusion in PubMed, CAS, Scopus and Google Scholar

- Research which is freely available for redistribution

Submit your manuscript at www.biomedcentral.com/submit
C Biomed Central 